\title{
Study of Effect of Seismic Excitation Angle for the Analysis of Regular and Irregular RC Frame
}

\author{
Rupali Jadhav ${ }^{1}$, Abhishek Jaiswal ${ }^{2}$ \\ ${ }^{I}$ (ME (Structure) Student, Department of CIVIL, Shreeyash College of Engineering \& Technology, India) \\ 2(Professor Department of CIVIL, Shreeyash College of Engineering \& Technology, India)
}

\begin{abstract}
As the location of the epicentre is not known, it is necessary to determine the response of a structure for all possible orientations of the principal axes and design for the largest or critical response. In this paper, study has been made to examine the influence of the earthquake excitation angle on different types of building. Regular and irregular shape of building with $G+9$ stories are considered.A set of values from 0 to 90 degrees, with an increment of 10 degrees, have been used for angle of excitation. Building columns have been divided into three categories, including corner, side, and middle. The output response parameter studied is axial forces in the column. The angle at which maximum axial force in column occurs, that angle is considered as critical angle. Theresults show that angle of seismic excitation considerably influences the response of structure.
\end{abstract}

Keywords: Angle of Excitation, Axial force of column, Plan Irregularity, Response spectrum analysis, E-Tabs.

\section{Introduction}

An earthquake can be explained in the horizontal plane as two orthogonal acceleration components of different intensities, which can excite a structure with any horizontal incidence angle. This situation is assumed in several codes considering two orthogonal components of equal intensities. Although in the seismic design of structures the directions of ground motion incidence are usually applied along the fixed structural reference axis, it is known that for most world tectonic regions the ground motion can act along any horizontal direction; therefore, this implies the existence of a possible different direction of seismic incidence that would lead to an increase of structural response. Critical angles are earthquake incidence angles producing critical responses.

Response spectrum is one of the useful tools of earthquake engineering for analysing the performance of structures especially in earthquakes. A response spectrum is a plot of the maximum response amplitude (displacement, velocity or acceleration) versus time period of many linear single degree of freedom oscillators to a give component of ground motion.

Several researchers have presented their study in area of maximum structural response associated to the directions of ground seismic motions in several papers. Lopez and Torres (1997) have tried to present a simple method, which can be applied to determine the critical angle of seismic incidence and the corresponding peak response of structures. In their method the seismic components are given in terms of response spectra that may be equal or have different spectral shapes. In that study the structures are discrete, linear systems with viscous damping.These proceduresare usually identified in technical literature as complete quadratic combination rule with threeseismic components or CQC3. Smeby and Der Kiureghian (1985) have presented some modal combination rules for buildings systems with linear behaviour subjected to multicomponent earthquake excitations based on spectral analyses. They have given two angles or directions of excitations one for minimum and the other for maximum response values. The calculated critical angles are not usually the same for various kinds of responses. They have claimed that the response spectra should be obtained for un-correlated direction to give proper results. Also see for Faramarz Khoshnoudian (2004), A.Pozos-Estrada1(2008), Mahmood Hosseini(2008).

\section{Frame Structure Details}

In this present study $\mathrm{G}+9$ building with different shapes including regular and irregular, are taken and dynamic analysis by using response spectrum method is done with the help of ETABS software. Building columns have been divided into three categories, including corner, side, and middle. The position of corner, side and middle columns shown in figure as $\mathrm{C} 1, \mathrm{C} 2, \mathrm{C} 3$ respectively.

Table 1: Specification of Models

\begin{tabular}{|l|l|}
\hline Type of structure & $\begin{array}{l}\text { G+9 storied } \\
\text { (RC moment resisting frame) }\end{array}$ \\
\hline Seismic zone & V, As per IS 1893 Part I, Z=0.36 \\
\hline Importance Factor & 1 \\
\hline Damping Ratio & 0.05 \\
\hline Imposed load & $2 \mathrm{KN} / \mathrm{m} 2$ \\
\hline
\end{tabular}




\begin{tabular}{|l|l|}
\hline Storey Height & 3.0 \\
\hline Specific Weight of RCC & $25 \mathrm{KN} / \mathrm{m} 3$ \\
\hline Specific Weight of Brick infill & $18 \mathrm{KN} / \mathrm{m} 3$ \\
\hline Infill Wall & $230 \mathrm{~mm}$ \\
\hline Corner column size C1 & $230 \times 450$ \\
\hline Side column size C2 & $230 \times 530$ \\
\hline Middle column size C3 & $300 \times 600$ \\
\hline
\end{tabular}

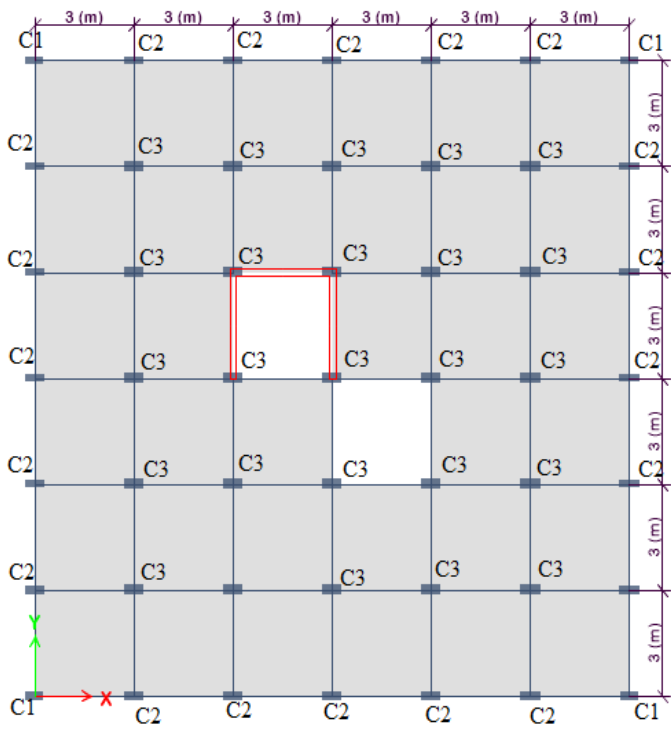

Fig. No.1: Square Structure

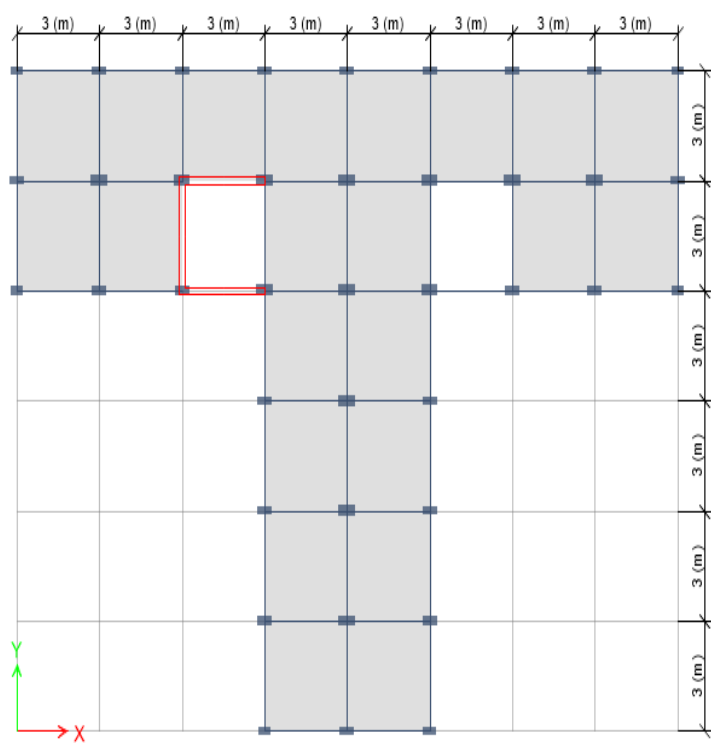

Fig. 2: T- Shaped Structure

\section{Methodology}

A response spectrum is a plot of the maximum response amplitude (displacement, velocity or acceleration) versus time period of many linear single degree of freedom oscillators to a give component of ground motion. The resulting plot can be used to select the response of any linear SDOF oscillator, given its natural frequency of oscillation. One such use is in assessing the peak response of buildings to earthquakes.

In this paper, ten storied building frame is considered with the provision of lift and staircase for performing response spectrum method of dynamic analysis. In order to apply forces in different angles, the structure has to be rotated with incidence angle from 0 to 90 degrees, with an increment of 10 degrees and axial forces in the column have been investigated in all cases. The columns have been divided into three main categories, including corner, side and internal (middle) columns and the results are compared. The corner columns are denoted as $\mathrm{C} 1$, side columns as $\mathrm{C} 2$ and middle columns as $\mathrm{C} 3$ as shown in figure no. 1.

\section{Results}

The following table no.2 represents the axial forces in corner $(\mathrm{C} 1)$, side $(\mathrm{C} 2)$, middle(C3) columns of square structure.

Table No 2: Represents the axial forces in corner, side and middle column of square structure.

\begin{tabular}{|l|l|l|l|}
\hline Degree & \multicolumn{3}{|l|}{ Axial Force } \\
\hline & Corner Column (C1) & Side Column (C2) & MiddleColumn (C3) \\
\hline 0 & -1572.623 & -2061.7303 & -2963.7186 \\
\hline 10 & -1611.631 & -2054.5541 & -2842.1803 \\
\hline 20 & -1635.077 & -2031.0664 & -2811.0683 \\
\hline 30 & -1643.992 & -1991.7104 & -2752.8663 \\
\hline 40 & -1661.981 & -1933.5433 & -3028.0415 \\
\hline 50 & -1677.571 & -1988.8201 & -3027.8245 \\
\hline 60 & -1676.653 & -2027.1218 & -3009.4748 \\
\hline 70 & -1658.563 & -2052.8872 & -2965.1114 \\
\hline 80 & -1623.582 & -2060.043 & -2843.6571 \\
\hline 90 & -1572.429 & -2061.7594 & -2963.7812 \\
\hline
\end{tabular}

The following table no. 3 represents the axial forces in corner $(\mathrm{C} 1)$, side $(\mathrm{C} 2)$, middle(C3) columns of $\mathrm{T}$-shaped structure. 
Table No 3: Represents the axial forces in corner, side and middle column of T-shaped structure.

\begin{tabular}{|l|l|l|l|}
\hline Degree & Axial Force & side & middle \\
\hline & corner & -1975.46 & -2619.77 \\
\hline 0 & -1473.93 & -2030.34 & -2659.61 \\
\hline 10 & -1573.9 & -2085.23 & -2651.69 \\
\hline 20 & -1675.58 & -2120.01 & -2649.29 \\
\hline 30 & -1757.09 & -2135.64 & -2648.6 \\
\hline 40 & -1815.3 & -2127.8 & -2630.18 \\
\hline 50 & -1849.91 & -1845.86 & -2629.68 \\
\hline 60 & -1650.04 & -1898.08 & -2632.31 \\
\hline 70 & -1582.66 & -1911.26 & -2630.36 \\
\hline 80 & -1492.53 & -1976.08 & -2631.65 \\
\hline 90 & -1482.65 & & \\
\hline
\end{tabular}

The following table no.4 and 5 are representing axial forces at critical angle and its percentage variation with respect to axial forces at 0 degree.

Table No 4. Represents axial forces at critical angle and its percentage variation of square structure

\begin{tabular}{|l|l|l|l|l|}
\hline $\begin{array}{l}\text { Column } \\
\text { No. }\end{array}$ & $\begin{array}{l}\text { Critical } \\
\text { Angle }\end{array}$ & $\begin{array}{l}\text { Axial forces at } 0 \\
\text { degree }\end{array}$ & $\begin{array}{l}\text { Axial forces at Critical } \\
\text { angle }\end{array}$ & $\begin{array}{l}\text { Percentage variation } \\
(\%)\end{array}$ \\
\hline C1 & 50 & -1572.62 & -1677.57 & 6.61 \\
\hline C2 & 0 & -2061.73 & -2061.73 & 0 \\
\hline C3 & 40 & -2963.71 & -3028.04 & 2.17 \\
\hline
\end{tabular}

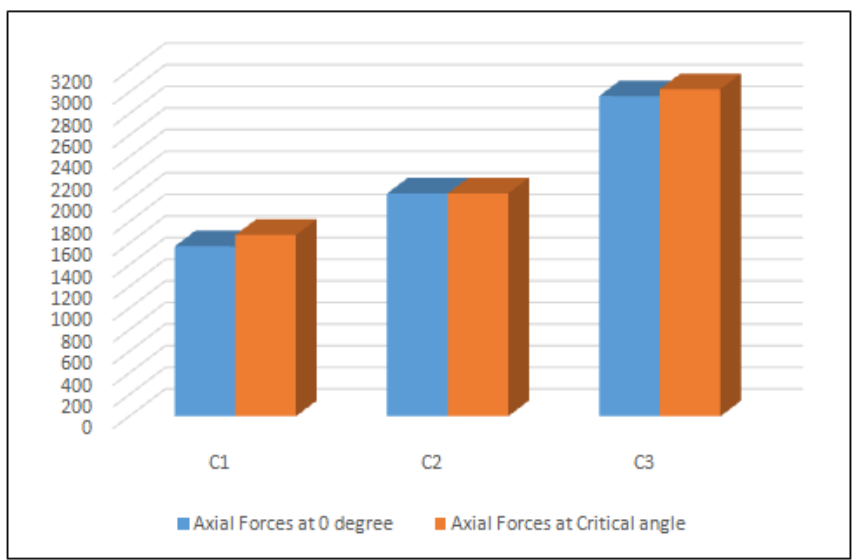

Fig. 3: Shows the difference between axial forces at 0 degree and at critical angle of square structure

Table No 5. Represents axial forces at critical angle and its percentage variation of T-shaped structure.

\begin{tabular}{|l|l|l|l|l|}
\hline $\begin{array}{l}\text { Column } \\
\text { No. }\end{array}$ & $\begin{array}{l}\text { Critical } \\
\text { Angle }\end{array}$ & $\begin{array}{l}\text { Axial Forces at 0 } \\
\text { Degree }\end{array}$ & $\begin{array}{l}\text { Axial forces at Critical } \\
\text { angle }\end{array}$ & $\begin{array}{l}\text { Percentage } \\
\text { Variation }(\%)\end{array}$ \\
\hline C1 & 50 & -1473.92 & -1849.90 & 25.51 \\
\hline C2 & 40 & -1975.46 & -2135.63 & 8.11 \\
\hline C3 & 10 & -2619.77 & -2659.60 & 1.52 \\
\hline
\end{tabular}

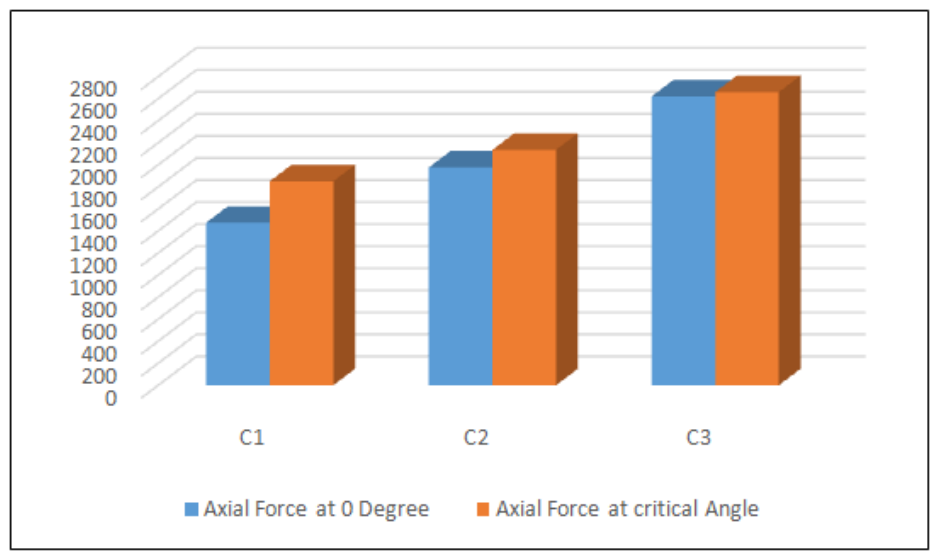

Fig. 4: Shows the difference between axial forces at 0 degree and at critical angle of T-shaped structure 
It is seen that from table No.2 and 3 that regular and ireegular structures have shown considerable increase in axial forces of columns. In both structure, maximum axial forces in corner, side and middle has occurred at different angle. Corner columns shows maximum response at 50 degree in both structure whereas, critical angle of side and middle columns are varying.

From Table No. 4 and 5 it is seen that percentage variation in terms of axial forces in T- shaped structure is more as compared to square structure.

\section{Conclusion}

1) It is concluded that regular i.e square structure and irregular i.e $\mathrm{T}$ shape structure has shown considerable variations in maximum axial forces of columns.

2) $\mathrm{T}$ shape structure has shows more variations as compared to the square shape structure. Therefore, it is inferred that regulare shape of structure gives the better performance at any angle of incidence.

3) In both structures corner columns has shown maximum response in terms of axial force at 50 degree angle. Variation in axial forces of side and middle columns are less as compared to corner column.

4) The above conclusions show that structure behaves in different manner for different shape of structure. Thus, the structure should be analyzed for each particular angle and it should be designed for maximum value of axial force.

\section{References}

[1]. Lopez, Oscar A. And Torres, R. (Sept. 1997). The critical angle of seismic incidence and the maximum structural response, Earthquake Engineering \& Structural Dynamics, Vol. 26,no. 9, pp. 881-894.

[2]. Mahmood Hosseini and Ali Salemi, "Studying the effect of earthquake excitation angle on the internal forces of steel buildings element by using nonlinear time history analysis", The 14th world conference on earthquake engineering, October 12-17, 2008.

[3]. GeorgeGeorgoussis. AchilleasTsompanos and TriantafyllosMakarios." Approximate seismic analysis of multi-story buildings with mass and stiffness irregularity", The 5th international conference of Euro Asia civil engineering forum, DOI:10.1016/j.proeng.2015.11.147.

[4]. Fernández-Dávila, I., Cominetti, S., and Cruz, E.F. (2000). "Considering the Bi-Directional Effects and the Seismic Angle Variations in Building Design”. 12th World Conference on Earthquake Engineering, E.Q.C., Auckland, paper 0435.

[5]. Angelo Marinilli and Oscar A.Lopez Professor, Instituto de Materials y Modelos Estrucutrales IMME Facultad de Ingenieria. Universidad Central de Venezuela. Evaluation of critical response and critical incidence angles obtained with RSA and RHA" The $14^{\text {th }}$ World Conference on Earthquake Engineering October 12-17, 2008, Beijing China.

[6]. Victor I. Fernandez-Devila 1 and Ernesto F. Curz " Study of the effect of in-plan asymmetry in multi-story buildings subjected to Uni and bidirectional seismic motions" 13th World conference on Earthquake Engineering, Vancouver B.C., Canada August 1-6, 2004, Paper No. 1042.

[7]. Faramarz Khoshnoudian and Mehdi Poursha "Responses of three dimensional buildings under bi-directional and unidirectional seismic excitations" 13th World conference on Earthquake Engineering, Vancouver, B.C., Canada August 1-6, 2004 Paper No. 55. 